\title{
The value of empirical generalizations in marketing
}

\author{
Dominique M. Hanssens ${ }^{1}$
}

Published online: 25 October 2017

(C) Academy of Marketing Science 2017

Modern marketing science started in the early 1960s, with Kristian Palda's path-breaking book on the econometric measurement of advertising effects on sales (Palda 1964). Since then, we have witnessed a proliferation of highquality articles and monographs on various marketing science topics. From an academic perspective, these publications have collectively built a theoretical knowledge base about marketing that is, for the most part, grounded in the academic disciplines of psychology, economics, mathematics, and statistics. Examples include the developments in consumer choice modeling, in behavioral decision theory, and in structural models. But how about the development of a managerial knowledge base? By that I mean a scientific basis for marketing executives to be able to project the likely outcome of a proposed marketing action or even a marketing strategy.

At a qualitative level, I would argue that such a managerial knowledge base already exists. In particular, we know the expected direction of top-line impact of, say, an increase in advertising (positive), in customer satisfaction (positive), or in prices (negative). However, that knowledge is insufficient to gauge the bottom-line impact of such marketing actions. Instead, we need quantitative measurement of the magnitude of the expected marketing effects in order to assess their consequences for short- and long-term profit or surplus (in the case of non-profit marketing). Only then will marketing be able to generate financial return metrics that meet the information needs of the $\mathrm{C}$-suite

Dominique M. Hanssens

dominique.hanssens@anderson.ucla.edu

1 UCLA Anderson School of Management, Los Angeles, CA, USA (mainly the finance function) in organizations and that elevate marketing from a cost center to an investment function. This is where empirical generalizations of marketing impact come to the rescue.

An empirical generalization is "a pattern of regularity that repeats over different circumstances and that can be described simply by mathematical, graphical, or symbolic methods" (Bass 1995). In a marketing context, empirical generalizations answer the question "what tends to happen to consumer behavior and, therefore, business performance, when a firm, brand or other relevant entity engages in a certain marketing behavior?" This editorial will focus on generalizations that relate to marketing decision making and business performance. Generalizations that focus on consumer processes are the subject of a book by Alba (2011).

Most of the empirical literature in marketing science uses a single database to make a particular inference. For example, Dekimpe and Hanssens (1995) illustrated the permanent (or trend-setting) impact of advertising spending on sales using a case study of a chain of home improvement stores. From a theoretical perspective, single-case empirics are generally sufficient, because they serve as illustrations of broader principles that are the focus of academic inquiry. In contrast, from a managerial perspective, single-case empirics are anecdotal in nature, i.e., any executive would rightfully wonder whether or not a planned advertising campaign will have an impact similar to that of the home improvement chain. However, when the results of such empirical studies are combined with those of dozens or hundreds of comparable studies, a meta-analysis (i.e., a study of studies) may reveal a replicable pattern in the data, which forms the basis for an empirical generalization that is much more informative to decision makers. To wit, Bijmolt et al. (2005) used 
the results of 1851 published price response estimates to conclude that average brand-level price elasticities ${ }^{1}$ are -2.62. Albers et al. (2010) collected 506 sales call response estimates to derive that sales call elasticities average 0.31 . Several other results of this nature may be found in Hanssens (2015).

I became aware of the importance of such empirical generalizations after the Marketing Science Institute (MSI) published the first edition of Empirical Generalizations about Marketing Impact in 2009. As editor of this volume, I had requested about 65 authors of peer-reviewed published empirical generalizations to summarize their findings in one page, following a prescribed template. Virtually all invited authors responded, and the resulting monograph quickly became the best-seller in MSI's Relevant Knowledge series. The book was designated a "Must Read" by Quirk's Marketing Research in 2013 and has since been updated in a 2015 edition. That second edition featured about 120 empirical generalizations, about $50 \%$ more than the original version.

Empirical marketing generalizations are of interest to both the academic and the practitioner communities. As our marketing doctoral programs increase in specialization and scientific sophistication, there is a risk that newly trained marketing academics are so focused on their area of expertise that they lack an overall perspective on marketing and marketing impact. A relatively quick scan of the available empirical generalizations can help remedy such problems. For example, a specialist on the modeling of advertising response effects may want to know that a different driver, product reviews, has a sales elasticity about six times that of advertising. Indeed, Sethuraman et al. (2011) reported an average advertising elasticity of 0.12 , whereas Floyd et al. (2014) listed an average product-review valence elasticity of 0.68 . Comparisons such as these are important as technology evolution makes the management of the marketing mix increasingly siloed, i.e., focused on a narrower and narrower subset of the entire marketing mix. As an example in an organizational context, companies that used to have a "Vice President of Sales and Marketing" now have a VP of each. Reporting to the Marketing VP may be a director of advertising. Reporting to that director is one manager of brand advertising and another for digital advertising. The digital advertising executive, in turn, may have subordinates in charge of "search," "social," and "mobile." The higher the specialization and proliferation of marketing tasks in our organizations, the stronger the need for a higher level view of marketing

\footnotetext{
${ }^{1}$ I use elasticity as a unifying metric of response. Since elasticity is percent change in response divided by percent change in effort, it is free of measurement units and as such can be used to make impact comparisons across the board. Note that elasticities less than 1 in absolute value imply diminishing returns to marketing, and those greater than 1 imply increasing returns. As such, elasticities are not only readily interpretable, but they also have major repercussions for marketing resource allocation.
}

impact, so that the relative contribution of each specialization may be assessed and managed.

The arguments above have attempted to make the case for the increased importance of marketing research that advances new or improved empirical generalizations. Two challenges face the academic community in that regard. First, doing empirical generalization work is very time consuming, typically more so than producing single-study papers. This challenge can be alleviated by creating publicly available meta-databases, such as the advertising elasticity database developed by Henningen et al. (2011). Second, since the work is focused on summarizing previously published studies, it may not be viewed as particularly creative by academic standards. Fortunately, published meta-analyses tend to be highly cited, which can be a powerful research incentive. Above all, though, there is a substantial need in the academic and practitioner communities to improve and expand the current inventory of about 120 generalizations in our field. In particular, we need new work in the following directions:

- Re-examining and sharpening the existing empirical generalization base, in particular developing rigorous conditions and moderators that impact an empirical generalization, so that we may appreciate the conditions under which the elasticity is above or below the average. For example, Sethuraman et al. (2011) describe a number of interesting conditions under which advertising elasticity is expected to be significantly higher or lower than its average 0.12 .

- Extending our knowledge base into the digital age. Digitization is rapidly engulfing all aspects of the marketing mix. As a result, new marketing definitions will emerge, for example around digital distribution and digital products (in particular the IoT, Internet of Things). Our empirical generalizations knowledge base on digital marketing is minimal at best, but the vast increase in quantity and quality of digital data creates many opportunities to change that limitation.

- Expanding our knowledge base to include other stakeholders such as firm employees, investors, and societal groups concerned with sustainability. Some work already exists in the area of investor response to marketing, using metrics such as stock returns and market value relative to book value. An excellent example in this context is the empirical generalizations paper by Edeling and Fischer (2016). Based on a review of 488 elasticities drawn from 83 studies, they report an average advertising $\rightarrow$ firm value elasticity of 0.04 and an average marketing assets $\rightarrow$ firm value elasticity of 0.54 .

Empirical generalizations are the quantitative equivalent of review papers, whose importance is described in the companion editorial to this issue (Palmatier et al. 2018). As the authors 
highlight, replicability is a key aspect of the structure of review papers, and the same holds for empirical generalizations. As the information age continues to deliver vast amounts of data, I hope the marketing science discipline will rise to the challenge of producing replicable quantitative insights based on these data.

\section{References}

Alba, J. W. (Ed.). (2011). Consumer insights: Findings from behavioral research. Cambridge: Marketing Science Institute, Relevant Knowledge Series.

Albers, S., Mantrala, M. K., \& Sridhar, S. (2010). Personal selling elasticities: A meta-analysis. Journal of Marketing Research, 47, 840-853.

Bass, Frank M. (1995). Empirical generalizations and marketing science: a personal view. Marketing Science, 14(3), G6-G19.

Bijmolt, T. H. A., van Heerde, H. J., \& Pieters, R. G. M. (2005). New empirical generalizations on the determinants of price elasticity. Journal of Marketing Research, 42(2), 141-156.

Dekimpe, Marnik G. and Dominique M. Hanssens (1995) The persistence of marketing effects on sales. Marketing Science, 14(1), 1-21.
Edeling, A., \& Fischer, M. (2016). Marketing's impact on firm value: generalizations from a meta-analysis. Journal of Marketing Research, 53, 515-534.

Floyd, K., Freling, R., Alhoqail, S., Cho, H. Y., \& Freling, T. (2014). How online product reviews affect retail sales: a meta-analysis. Journal of Retailing, 90(2), 217-232.

Hanssens, D. M. (Ed.). (2015). Empirical generalizations about marketing impact (2nd ed.). Cambridge: Marketing Science Institute, Relevant Knowledge Series.

Henningen, S., Heuke, R., \& Clement, M. (2011). determinants of advertising effectiveness: the development of an international advertising elasticity database and a meta-analysis. BuR-Business Research, 4(2), 193-239.

Palda, K. S. (1964). The measurement of cumulative advertising effects. Englewood Cliffs: Prentice-Hall.

Palmatier, R. W., Houston, M. B., \& Hulland, J. (2018). Review articles: purpose, process, and structure. Journal of the Academy of Marketing Science, 46(1). https://doi.org/10.1007/s11747-0170563-4.

Sethuraman, R., Tellis, G. J., \& Briesch, R. A. (2011). How well does advertising work ? generalizations from meta-analysis of brand advertising elasticities. Journal of Marketing Research, 48, 457-471. 